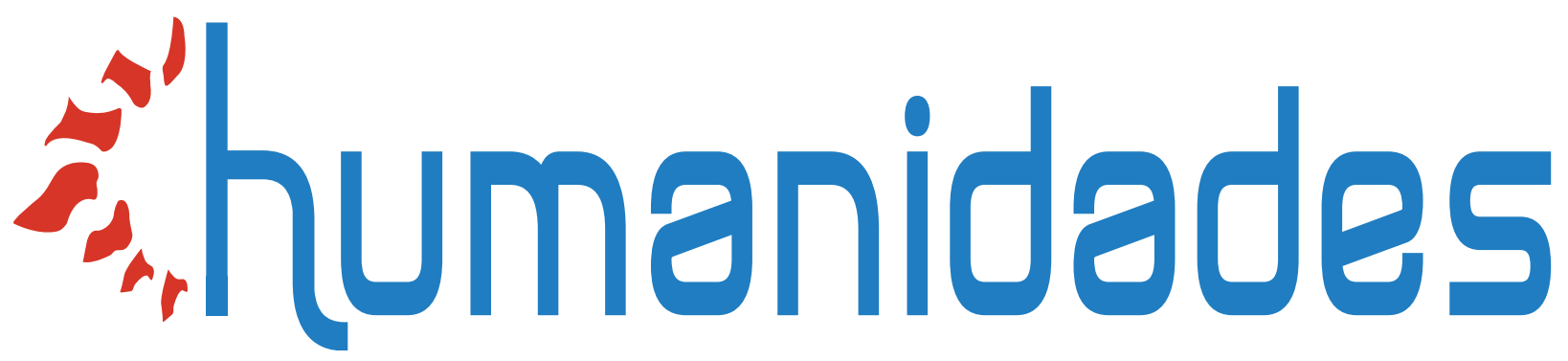

\title{
El decir y el pensamiento
}

\author{
Benjamín Valdivia
}

\begin{abstract}
DOI: https://doi.org/ I0.155 I7/h.v10i2.4II 29 https://revistas.ucr.ac.cr/index.php/humanidades/index

(c) $(7) \Theta$
\end{abstract}

Universidad de Costa Rica 


\title{
"humanidades
}

Revista Humanidades

ISSN: 2215-3934

humanidades@ucr.ac.cr

Universidad de Costa Rica

Costa Rica

\section{El decir y el pensamiento}

\author{
Valdivia, Dr. Benjamín \\ El decir y el pensamiento \\ Revista Humanidades, vol. 10, núm. 2, 2020 \\ Universidad de Costa Rica, Costa Rica \\ Disponible en: http://www.redalyc.org/articulo.oa?id=498062469002 \\ DOI: https://doi.org/10.15517/h.v10i2.41129
}

Esta obra está bajo una Licencia Creative Commons Atribución-NoComercial-SinDerivar 3.0 Internacional. 


\title{
El decir y el pensamiento
}

\author{
Saying and Thinking \\ Dr. Benjamin Valdivia \\ Universidad de Guanajuato, México \\ valdivia@ugto.mx \\ (iD) http://orcid.org/0000-0002-6444-1476
}

DOI: https://doi.org/10.15517/h.v10i2.41129

Redalyc: http://www.redalyc.org/articulo.oa?

\section{RESUMEN:}

El pensamiento es comprendido a partir de su expresión mediante un lenguaje, lo cual permite que las comunidades intercambien información útil para su continuidad. En el presente texto, las partes que componen ese proceso de intercambio son analizadas en sus implicaciones formales y vitales, de esta manera se observa el desplazamiento del ser al pensar, del pensar al decir, y de este al diálogo entre decires, que al fin se resuelven como diálogo entre personas, para fortalecer el lazo social. Sin embargo, el fuero interno del individuo también entra en esta consideración.

Palabras ClaVE: lenguaje, comprensión, pensamiento, diálogo.

\section{Abstract:}

Thought is understood from its expression through language. It allows communities to exchange information useful for their continuity. In this paper, components of this exchange process are analyzed both in their formal and critical implications, emphasizing the shift from being to thinking, from thinking to saying, and the dialogue between sayings, that finally results in a dialogue between persons, strengthening the social ties. However, the inner self of individuals also enters into this consideration.

KEYWORDS: language, understanding, thinking, dialogue.

\section{INTRODUCCIÓN}

El poeta Vicente Huidobro, en su Altazor (2006, párr. 496), pregunta: “¿Por qué hablas Quién te pide que hables?" Este poema extenso es un hablar largo que dentro de sí contiene para nosotros la pregunta por la exigencia del decir: ¿quién nos pide que hablemos? En su inicio, la vida comienza sin hablar. Cuando se nace, no se nace hablando. El decir es algo que luego se aprende. De tal modo, la primera consideración a tomar en cuenta es la siguiente: el decir es algo aprendido. El decir no le pertenece a la naturaleza. Sin embargo, cuando observamos diferentes grupos de animales, aparte del grupo humano, notamos que también tienen ciertas comunicaciones que, a su modo, expresan. Hemos escuchado el grito de la bestia, el chillido del perro cuando se golpea con algo. Pero el decir tiene otras cualidades más allá del grito o el chillido. La primera, como queda dicho, es que el decir es una cosa adquirida. Es adquirida por cada uno, porque no le pertenece al individuo: el decir es siempre cosa de otros. Siempre hay un momento entre dos personas para que pueda existir el decir. No me refiero al acto de pronunciar, pues se puede pronunciar a solas. Pero, cuando uno pronuncia a solas, ¿qué se está diciendo? Se pronuncia algo que muy bien podía prescindir de ser pronunciado. Este decir involucra fundamentalmente al lenguaje. Lenguaje que, por cierto, no le pertenece al que acaba de llegar al mundo, al que nace, sino que el decir les pertenece a los demás.

\section{DESARRollo}

El lenguaje es lo que los demás le otorgan al que acaba de llegar. Esto es cierto porque el idioma que aprendemos - por ejemplo, el español adquirido en nuestra primera infancia- implica que ya hay cierta forma de decir que nos pertenece. Si hubiéramos nacido en otro lugar o siendo muy pequeños nos hubieran 
hablado en otro idioma, entonces nos daríamos cuenta de que este decir se nos ha otorgado. Y a la vez que el idioma, ese regalo de nuestra comunidad, es ya nuestro y nos amplía hacia la significación, también nos limita, porque de ahí en adelante pensamos mediante esa lengua: este pensar en español. Hay cosas que, precisamente por hablar español, nos resultan difíciles de pensar.

Ahora bien, para decir algo en español, usamos todo tipo de vueltas, formalismos o circunloquios. Por su parte, idiomas como el inglés que cuentan con gran cantidad de monosílabos y onomatopeyas, puede tener usos más prácticos. Además, hay idiomas como el alemán, que suman partículas para que las palabras tengan otro significado. Esos idiomas otros permiten pensar de otro modo. Claro que los hablantes nativos de aquellas lenguas también tienen esos límites que les son propios.

Un primer punto, pues, sería la asunción de que el idioma no nos pertenece como individuos, sino que la sociedad lo otorga. Y un segundo aspecto, mediante ese don, nos limita. Nos restringe a pensar conforme a cómo ese idioma está hecho. Por ejemplo, en alemán, apfel ${ }^{1}$ significa 'manzana', al añadirle otra parte, se forma apfelsine, que significa 'naranja'; si le agregamos algo más, quedaría apfelsinensaft (jugo de naranja) o apfelsinenscheibe (rebanada de naranja) y así sucesivamente vamos elaborando el significado con nuevos añadidos. En dicho ejemplo, se debe notar que en castellano son tres palabras: manzana, naranja y jugo de naranja; además, en castellano, no se ve ese fondo de relación originaria con el resto de las frutas, como sí ocurre las palabras citadas en alemán que en su inicio la referencia del apfel.

Por tanto, hay un cierto modo de pensar que se articula en un cierto modo de decir. Y eso es lo que queremos contar y lo que queremos ver: nuestra historia y nuestro porvenir. Una vez que el idioma ya reside dentro de nosotros, una vez que el idioma, nos obligó a dejar de ser lo que éramos en la mudez primigenia y nos obligó a dejar de ser nosotros a solas para convertirnos en aquellos que ya son parte de un grupo idiomático dado, esto, digo, nos otorga una cualidad: el lenguaje. Pero el hablar nos saca de nosotros mismos. Entonces, ¿cuál es el motivo del hablar? Se puede, quizás, tener una respuesta provisional a la pregunta de Huidobro. ¿’Por qué hablas?: porque necesito salir de mí mismo. ¿Quién te pide que hables?: el conjunto social que me ha otorgado el idioma y me pide que me muestre como parte de él.

Claro que los lingüistas, ya desde el Cours de linguistique générale de Saussure, tienen muy claro que la lengua es una propiedad colectiva. Sin embargo, una de las cosas relevantes que se discuten en la filosofía analítica, en el siglo XX, es si acaso es posible tener un lenguaje privado: si puedo hablarme a mí mismo en un idioma que no le pertenezca a nadie más. Esto es, si acaso podemos decirnos algo que no pase por lo que el idioma nos está obligando a decir/nos: hablar en una lengua mía, que no sea colectiva. El lenguaje nos pide que salgamos de nosotros mismos. Dicho de otro modo: el que habla, está fuera de sí. Y, desde luego, el que está fuera de sí es como un loco. Por tanto, hablar sería una locura; no obstante, hablamos. Hablamos porque tenemos una confianza en que los otros están escuchando. Mas esa confianza no siempre se ve colmada. Todos hemos oído-o incluso hemos emitido- la frase: "perdón, no te estaba escuchando". Esa frase equivale a la interrogación “¿quién te pide que hables?”. Es decir: ¿por qué estás hablando? Y, en el fondo, es pregunta por el sentido: ¿qué estás diciendo? Todas estas expresiones que el idioma nos plantea son los elementos en los que se puede tener claro cuál es el mundo que está ahí. La cuestión irresuelta es si el hablar nos saca de nosotros mismos, puesto que, incluso en nuestro fuero interno, nos extrae del mundo privado y nos instaura en el mundo de los otros, en el de una colectividad que habla ese idioma que hablamos.

Así las cosas, ¿cómo vamos a llegar a nosotros mismos? Es decir, ¿cómo nos vamos a hablar/nos a nosotros mismos, si ejercer el idioma nos extrae de nosotros, y no nos pertenece, sino que es de los otros? Quizás uno de los grandes problemas de la existencia - la angustia de ser humano- viene de una cierta imposibilidad de comunicarnos absolutamente con nosotros mismos: tener la certeza de no podernos decir todo a nosotros mismos. El psicoanálisis sería el ejemplo más claro de los artilugios culturales que inventamos para dar a conocer al otro: que el otro sepa de sí mismo mediante el decirme a mí; que lo que para él es inconsciente se vuelva consciente al dármelo a comprender. 
Si hablar es una locura, entonces lo más cuerdo sería guardar silencio. Callar parecería ser lo más sensato. Sin embargo, una vez que tenemos el idioma en nosotros, parece ser que ya no podemos pensar sino a través de los recursos idiomáticos. En lo personal, más o menos de modo sistemático, me he sometido a la experiencia de intentar pensar prescindiendo del idioma; he intentado pensar en otros idiomas; he intentado pensar otras cosas en español. Estos experimentos me han llevado a plantear muchas dudas, no respecto del idioma sino de nuestra capacidad como seres humanos para poder vencer esta incapacidad de vencer al lenguaje en el pensamiento. Entonces, parece que estamos obligados a decir. Y este decir - que nos saca de nosotros mismos y que le pertenece a la comunidad - nos separa de lo que realmente nos interesa: nosotros. Parto de asumir el principio de que toda vida es individual: cada uno de nosotros, aquí y en cualquier lugar del mundo, vive su propia vida; y nadie más vive esa vida; y uno no vive la vida de nadie más. Puede valorarse como sea: existencialismo, egoísmo, individualismo, como se quiera llamar. Pero, hasta este momento, no hemos sabido de una persona que viva a la vez dos vidas. Claro que hay vidas escindidas, esquizofrénicas, bipolares; pero no me refiero a eso, pues lo que quiero decir es que esa escisión, esquizofrenia o bipolaridad le pertenece a una sola persona, que es quien vive la ruptura, y no le pertenece a otras personas. Entonces, como cada vida es individual, ¿cómo la vamos a comprender del todo, si el lenguaje ya es social, colectivo, hecho para significar lo que no es mi individualidad? Esto plantea graves problemas que los filósofos de todos los tiempos han tratado de elaborar: algo que nos conduzca a la primicia del pensamiento para conocerse a sí mismo.

Si nos pudiéramos conocer a nosotros mismos, tal como lo exigía el pórtico del templo, podríamos conocer el universo y los dioses. Excepto que no podemos por varias circunstancias. Principalmente porque el lenguaje no nos ayuda. Y confiamos demasiado en el lenguaje como para conocernos a nosotros mismos. Mediante el lenguaje nos conocemos muy poco. En este conocerse muy poco, en este darle vuelta a la página y saber que no vamos a ser lo que queríamos ser (o hacer), vemos la dificultad real del conocerse a sí mismo. Este conocerse, como afán filosófico, es el motivo de las vidas de los grandes pensadores. Sócrates, en el ágora ateniense, preguntaba a los otros, esperando conocerse a sí mismo. Sin embargo, por más que buscamos en las crónicas históricas, en los textos de Jenofonte, en los de Platón, no se encuentra una pista exacta de cómo hacer para conocerse a sí mismo. Al término, Sócrates concluye que el asunto no está zanjado del todo. De lo mostrado por dicho pensador, parece que estuviésemos condenados a una búsqueda que no va a ser posible consumar. No podremos concluirla; pero la podemos decir: los pensadores sospechaban ya que lo pensado no lo puedo expresar; y si lo expreso no coincide con lo que se escucha; y, todavía más, lo que se entiende a partir de eso que se escucha no tiene relación completa con lo escuchado. Esos maestros atenienses advierten que lo único que se puede tener claro es la duda (o la ignorancia). Lo único de lo que nos daremos cuenta es que nada sabemos; o que todo es dudoso. Y, por lo tanto, nosotros también. Así, ¿qué puedo afirmar, si soy un ser dudoso? Si cada uno de nosotros es una duda, ¿qué podemos afirmar? Lo que podemos afirmar es una pregunta. Tendríamos que concluir esto: cada uno de nosotros es una interrogación. Lo que podemos hacer, a fin de conocernos a nosotros mismos, es expresar la pregunta, formular la interrogación de quién soy yo. Dice el poema: “Te amo, pero, ¿quién soy yo?”. Ya dije que te amo; excepto que no sé quién soy: no sé quién es quien te ama. No que no sepa quién soy yo para decirlo, sino que yo, que amo, no sé quién soy. Vemos que el sujeto de todo lo que decimos, hasta en la más honda declaración de amor, empieza a quedar en duda.

La filosofía, en especial la de Occidente, trata de decir todo con claridad. Si tomamos en cuenta esta conclusión intermedia, a la que hemos llegado, de que cada persona es una interrogación, diríamos que dos personas que dialogan lo único que pueden hacer es interrogarse o declararse a sí mismos como interrogantes. Ahora bien, por más que dialogamos con una persona, nunca vamos a conocerla. Quien lo dude, pregunte a los matrimonios largos: la gente dialoga, platica, y al final nos recuerda que no se entiende, que viven juntos pero cada vida es individual. Viven juntos, hablan todos los días, probablemente conversan todo el día, sin embargo, allí está faltando algo. ¿Qué es lo que falta? Mi consideración es que lo faltante es el pensamiento, el pensamiento que nos conduce a esa interrogación (pues el otro también es esa interrogación). Para conocernos a nosotros mismos, antes de expresarnos como una duda, antes de ser una duda que se expresa, 
muy bien podíamos ser alguien que piensa. Descartes descubre que él es una cosa que piensa; ni siquiera un humano sino una cosa, cosa pensante: "Je suis une chose qui pense" (s.f). Pensante, sí, pero cosa. Dicha expresión es una de las más espectaculares declaraciones del ser: el ser es una cosa: en el ser que se piensa, el ser es una cosa pensante. Los pensadores alemanes, bajo la égida del Romanticismo, lo retoman de modo más elegante y dramático: el que piensa no es una cosa, sino un ser arrojado al mundo. Lo que plantea la filosofía es que, antes de dudar - y esa duda viene antes de decir - ya se es una cosa. Ya es, digámoslo así, un mero existir, un estar echado sobre el mundo. Pero en este existir, que duda - y que luego lo expresa—, se nota un proceso, que es el del pensar. Un proceso en el cual pensamos esto que es, pero que se expresa como una duda y que luego manifiesta de algún modo ese ser y esa duda.

Tanto en Oriente como en Occidente se han planteado sendas pedagogías del pensar, completísimas paideias que indican qué es lo que debemos hacer. El criterio general de estos maestros es que debemos pensar. Coincidiremos todos en que sería bueno pensar. No decir las cosas sin pensar. Se escucha con frecuencia esta frase: "lo dije sin pensar", en un lance in extremis, la frase se ofrece como una disculpa. Como si tuviéramos que pedir perdón por lo que somos; es decir, por lo que expresamos. Estamos ante dos pedagogías diversas: una que lo dice, aunque el pensamiento (a causa del lenguaje) sea insuficiente para decirlo; y otra que lo calla, aunque el pensamiento haya tocado el ser (sin tener lenguaje para decirlo). En ambos extremos, la conclusión es la insuficiencia para declarar lo que es. Ante el tópico de la libertad, un maestro dictará la cátedra de qué ha hecho el lenguaje con el pensamiento acerca de la libertad; y el otro mencionará la palabra 'libertad' y dejará que los demás piensen por horas. Ya sea que el interlocutor reciba un extenso discurso o solo una breve palabra, el lenguaje estará gobernando al pensamiento.

Hay un punto de vista sobre el silencio que quizás en Occidente todavía no se ha sabido sopesar: callarse antes de. Antes de dudar, antes de decir, antes de interrogar al ser, antes de preguntarme quién soy. Esto no implica, desde luego, que los filósofos del decir no estén en lo correcto. Han planteado correctamente la duda: “¿quién soy?”. Han planteado lúcidamente la respuesta: "soy una cosa”. Han delimitado la diferencia de qué tipo de cosa: "una cosa que piensa". No es que no tengan razones para lo que hayan hecho; solo se trata de pedagogías distintas - y 'pedagogía' significa conducir a los niños-. De especial importancia, en esta pedagogía del decir, resulta el diálogo, la dialéctica como forma de tratar de reconocernos a nosotros mismos por medio de nuestra expresión ante los otros. No estoy seguro de que el diálogo nos lleve a conocernos a nosotros mismos, pero sí de que lleva a reconocernos. Evoquemos aquella intensa frase de Hölderlin, analizada con tanto ahínco por Heidegger "desde que somos diálogo" (2001, p. 33) ${ }^{2}$. Eso dice el poeta. No solo está pronunciando el poema para sí, sino que el poema es compartido, lo cual nos constituye en un diálogo: nos hace ser diálogo "Gespräch wir sind". Al entregarnos las palabras del poema, nos está entregando el campo de los significados, que no solo nos pertenecen a nosotros que escuchamos, sino también al poeta y los que atienden al poema, pues las palabras que alguien dice fuera de nosotros se convierten en búsqueda de sentido en nuestro interior; al decir del poeta, nos hacen escucharnos mutuamente, que en alemán se diría "Und hören können voneinander".

Como prueba de que no es privativo de Occidente este asunto de cómo el lenguaje invade nuestros sentidos y nos convoca a buscar en nosotros el significado mediante el propio lenguaje, el que hemos interiorizado, convendrá citar The Book of Tea, escrito en inglés por el autor japonés Okakura Kakuzo, publicado en 1906, en la parte donde describe los componentes del salón ceremonial:

In order to understand a masterpiece, you must lay yourself low before it and await with bated breath its least utterance. An eminent Sung critic once made a charming confession. Said he: "In my young days I praised the master whose works I liked, but as my judgment matured I praised myself for liking what the masters had chosen to have me like." (Okakura, 2001, p. 47) ${ }^{3}$.

Es decir, desde que somos un diálogo, desde que podemos elogiarnos mutuamente, pues, aunque uno haya producido el poema, el otro fue capaz de entenderlo. Pero el acontecimiento de ser un diálogo puede verse 
interrumpido por las diversas incapacidades individuales, ya sea para expresar o para comprender. Aun así, su validez estructural continúa, porque el lenguaje también se apodera del tiempo, pues queda a resguardo de los signos impresos o registrado en medios de tecnologías acústicas. De modo que los habitantes del futuro cuenten con la posibilidad de convertir el signo abstracto del lenguaje en una verdadera devoración de nuestro ser en el momento próximo, cuando seamos un diálogo. Eso es notorio en el Poema 91 de Stephen Crane, pirata, reportero y escritor muerto en 1900, a los 28 años:

Poema 91

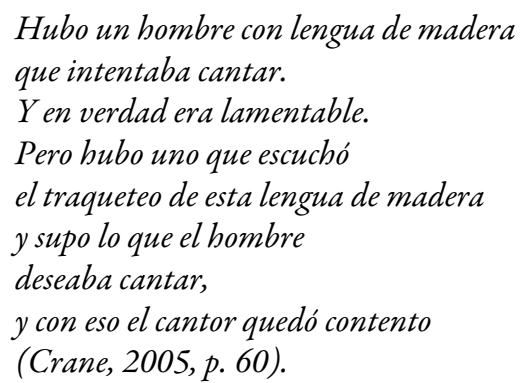

En este poema de Stephen Crane, o en la declaración de Hölderlin, o en la afirmación de Okakura sobre la comprensión, notamos que las pedagogías del silencio y las del diálogo suceden en todo el mundo, en todo tiempo. Sin embargo, queda la duda de lo que digo, que ya no es lo que pienso. Pienso algo y cuando lo digo, la forma de la expresión se ciñe a otro modo de decir, uno que no es mental. Por ejemplo, cuando se quiere afirmar algo en inglés y también en español la divergencia de expresiones muestra que no hay fidelidad, que lo dicho no es lo mismo que se pensaba, ya que siempre algo se pierde en la traducción. Si digo y ya no es lo que pienso; escuchas y ya no es lo que digo, como señala Protágoras, parece que el diálogo conlleva serias dificultades. Por tanto, tenemos que detenernos a analizar el diálogo mismo, su dialéctica.

La dialéctica otorga mi modo de decir a tu modo de escuchar. Si tenemos suerte y logramos ser un diálogo, tu modo de decir se otorgará a mi modo de escuchar. Por ejemplo, Alatorre y Escalante sostuvieron una argumentación en torno a la crítica literaria (Alatorre, 1993, pp. 109-130), uno postula que la palabra, es decir lo que se dice, es a lo que hay que hacerle crítica: una crítica de lo que se dice; el otro, más germánico, asume que a ese decir hay que sumarle el peso de escuchar. Ciertamente, lo que se discute, en el fondo, parte de que "en el principio era el verbo". Si Dios se expresó con palabras, entonces se supone que habría alguien a la escucha, pues de lo contrario no sería un diálogo, no sería un uso real del lenguaje; es decir no sería un lenguaje que le perteneciera a ese ponerse en común que corresponde a todo lenguaje. ¿A quién le dice Dios que se produzca el universo, que se haga la luz? ¿A alguien se lo dice? No nos referimos al acto cósmico de la creación, que ha de ser asunto de teología o metafísica, sino a las palabras que lo refieren, en específico el "Génesis". Desde su textualidad, las palabras que refieren la creación nos dicen que Dios dijo. Lástima que no nos dicen si Dios lo pensó antes de decirlo. Como se observa en el siguiente Poema 6 de Crane. Se considera que Dios no lo pensó, que el barco del mundo se le fue de las manos, por lo cual andamos a la deriva con la creencia de que tiene un sentido todo esto:

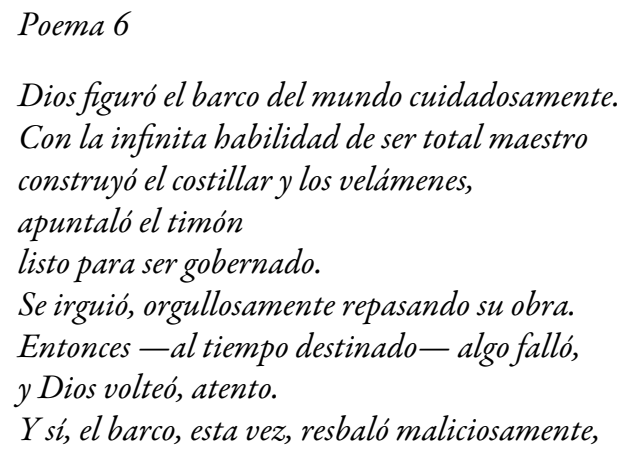




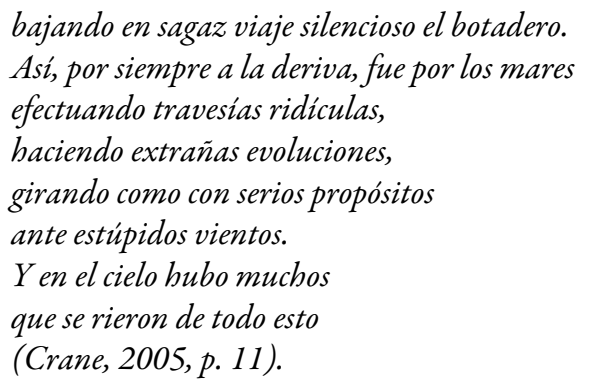

Sin embargo, no queda claro en el tema entre Alatorre y Escalante si el verbo presupone el oído, o si el oído no hace falta para el verbo. La cuestión estriba en que, si el lenguaje es siempre para alguien más, entonces no sería para mí mismo. Planteado de otra forma: yo no me digo a mí mismo las palabras que me digo, pues el lenguaje no es para mí. Las pronuncio para mí, sin duda, pero al hacerlo se las estoy diciendo a alguien más. Las estoy diciendo al que escucha.

Estas pedagogías implican que alguien se apropia del decir y alguien se apropia del no-decir, o al menos de su fase pasiva, el escuchar. En la antigua escuela de Pitágoras existían ambos grupos: los matemáticos y los acusmáticos. Los primeros sabían interpretar los símbolos y decirlos, mientras que los segundos son receptores de la acústica y debían saber escuchar el discurso de quienes interpretaban los símbolos. Esto nos plantea, previo al escuchar, dos cosas: el interpretar los símbolos y el decir cosas se reducen, básicamente, al pensar. La antigua escuela contendría a los que piensan y a los que escuchan a los que piensan. Eso nos revela el orbe en que Pitágoras se mueve: cuando algo se dice, es que ya se dejó de pensar y ahora se está diciendo. Al decirse, se planta en los campos de la retórica, en cuanto que decir algo es afirmar un cierto modo de decir. La retórica es el modo en que fluye el decir ${ }^{4}$.

La retórica es la forma de lo que fluye y esto que fluye es, precisamente, el lenguaje. Aristóteles, en la primera frase de su Retórica, afirma que la retórica es complementaria de la dialéctica ${ }^{5}$. Ya que se encuentra en función

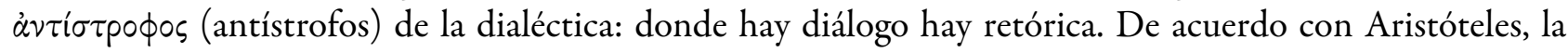
retórica es la que, al cumplirse su tiempo, se pone en lugar de la dialéctica. A la vista de lo expresado por Hölderlin, tendríamos que reconocer, detrás de la afirmación "desde que somos diálogo", su antistrofa: "desde que somos retórica". No "desde que somos dialéctica", sino "desde que somos retórica", porque incluso cuando no hay diálogo, en cuanto fluye el lenguaje ya hay retórica. Podría no encontrarse el sentido de la frase, pero la expresión de la frase ya es innegable: lo que digo es nada, pero está ya dicho. Aristóteles, al avanzar la idea contenida en esa primera frase, revela la asociación de la retórica con el deseo de expresar, aunque no necesariamente de significar: "todos quieren o averiguar o sostener una razón" (Aristóteles, trad. 2002) ${ }^{6}$. Estamos ante las dos posiciones de lo que los filósofos intentan: pensar y decir. Por un lado, quieren sustentar razones por medio del discurrir; por otro, quieren averiguar de qué se trata eso discurrido, cuál es su sentido. Por eso se usa el lenguaje para analizar el lenguaje, incluso con metalenguajes.

La lógica no se ocupa de lo pensado sino de lo enunciado. Hace mucho que los lógicos renunciaron a investigar lo que se piensa; han dejado que eso sea materia de psicólogos y otro tipo de gente. La lógica aspira a la objetividad de las formas; su justicia estriba en aplicar valores de verdad a cada componente de lo dicho, no de lo pensado. Por ejemplo, al analizar el enunciado 'los gatos son breves', se puede calcular la predicación y demás procedimientos formales, y hasta matemáticos, pero no habrá modo de que los gatos dejen a un lado su brevedad. ¿Acaso no es importante lo que se dice, sino las fórmulas del decir? Sin embargo, si hemos de creer a Aristóteles, y a muchos más, cuando nos interesan las fórmulas del decir, estamos en plena retórica, no solo en la dialéctica. Y por más que se analice con símbolos matemáticos, nos referimos al fluir, a cómo fluye el lenguaje. No a su verdad, sino a su corrección: las tablas de verdad utilizadas en la lógica son para determinar las fórmulas en las que lo expresado se aproxima a la corrección. Así, la argumentación, con toda la lógica que se implique en ella, pertenece finalmente a la retórica, que bien resulta, como queda dicho, antistrófica de la dialéctica. 
Lo que tenemos, hasta donde vamos, es algo que suena igual a un proverbio árabe: "el que habla está regalando lo que no es suyo" (s.f). Y es que, como quedó a la vista, el lenguaje pertenece a los demás. Quiero decir: hasta mi lenguaje le pertenece a los demás. Por su origen o por su destino: los demás inventaron las palabras. Cuando yo llegué al mundo, ya existían las palabras. La palabra 'palabra' ya existía, lo mismo la palabra 'yo', la palabra 'llegué, la palabra 'mundo'. Cuando yo llegué al mundo, la palabra ya existía y todo lo que uso para expresarme es algo que no me pertenece. Ya que estoy regalando lo que no es mío, por tanto, nadie habla con propiedad.

Sin embargo, con todo lo impropio que pueda ser el lenguaje, hay algo de mayor fondo, a lo cual podemos denominar, de un modo semipoético, "la dádiva del discurso". El discurso nos es dado; por eso los filósofos del lenguaje, en especial los que tienden hacia la hermenéutica, lo han visto así. El lenguaje es una dádiva. Lo que interesa indagar es cómo se da el lenguaje. Cuando alguien habla, lo que hace es dar a entender: buscar que el otro comprenda lo expresado. No obstante, por lo mencionado párrafos arriba, surge esta interrogante: ¿cómo lo va a comprender si ambos somos una duda? Lo que puede hacer quien escucha es hacer suya la duda de la expresión del otro. La expresión discursiva únicamente nos puede llevar hacia la crítica del discurso. Esa dádiva implica su propia destrucción o por lo menos su propia crítica. Justamente, hay un peligro oscuro en este proceso: cuando una persona da a entender, parecería que ella misma ya entendió, así que, como ya lo entendió, ahora lo puede dar a entender. Porque, en esta paideia de la duda, ¿cómo voy a dar a entender algo que yo mismo no comprendo? Hay una especie de dilema involucrado: si no lo he comprendido, no lo puedo dar a entender; ahora bien, si ya lo entendí, y lo doy a entender, parece que estoy regalando algo que no es mío: dije algo impropio. Quisiera pensar que quien da a entender, que, por lo tanto, dice lo que se entiende, tiene ya una comprensión silenciosa: por sí mismo sabe algo y lo da a entender. Si no posee esa comprensión, es imposible darla, pues estaríamos donando el discurso y no el entendimiento. De ahí que la filosofía, antes de ser un discurso, antes de decir, necesite ser una comprensión. En todo caso la lógica, la dialéctica y la retórica forman parte del orden social del pensamiento — de la filosofía - que está ligado en puntos principales al lenguaje ${ }^{7}$. En el pensar se involucra una comprensión y ahí donde está la comprensión puede no estar todavía el lenguaje, por lo menos no como un decir. Sin embargo, está dentro de nosotros, obligándonos a no salir de los límites de ese lenguaje (que ya entendimos) que ya tenemos nuestro, de esa retórica del lenguaje nuestro. Esa comprensión silenciosa, en caso de existir —apuntémoslo como hipótesis, para no atar más cabos-, nos plantea dos aspectos: uno subjetivo, que no necesita salir, al que podemos llamarle comprender; el otro es intersubjetivo, que compete al decir. Subjetivo: comprender. Intersubjetivo: decir. En otras palabras, el diálogo enfrenta al sujeto con los demás sujetos, lo subjetivo con lo intersubjetivo: decir lo que se comprende y comprender lo que se dice.

Nadie puede comprender las cosas por mí: en lo que me compete, solo yo puedo comprender las cosas de mi vida, lo que me dice el discurso de los demás, lo que interpreto de los libros, de la visión de las películas, de las experiencias del amor, de lo que se quiera. Cada uno, en esa vida individual, en esa comprensión silenciosa -forcemos las cosas y llamémosle "comprensión estética" - , se siente seguro de ser, puede afirmar o suponer que sí hay una comprensión interior. Pero cuando lo decimos, y en tanto que el lenguaje les compete a los otros y me saca de mí mismo, en tanto que el lenguaje es una herencia y algo que ya existe, pues solo lo comparto en la medida de lo que me es posible,para darlo a entender al otro. Por eso la poesía, que es un lenguaje que fuerza las cosas del idioma, nos conduce a una mayor comprensión; y probablemente hacia algo indecible. No vamos a insistir en el tema de lo indecible de la poesía, que es asunto para otra jornada. Pero sí hagamos notar que, por ejemplo, el poema Árbol adentro (2004) de Octavio Paz dice en su primera parte:

\author{
Arbol adentro \\ Creció en mi frente un árbol. \\ Creció hacia dentro. \\ Sus raices son venas, \\ nervios sus ramas,
}


sus confusos follajes pensamientos.

Estos confusos follajes, que son pensamientos, no aparecen en las investigaciones científicas ni en los libros de anatomía. En la observación del cuerpo o en especial del cerebro, tampoco se ven estos confusos follajes que son los pensamientos. Pero allí están, en lo dicho por el poeta: esos pensamientos solo se ven cuando se dicen. Como queda señalado, al decirlos ya están fuera de sí. Dado que siempre la argumentación se refiere a lo enunciado, quedamos puestos ante la pregunta siguiente: ¿quién se ocupa de lo pensado? De lo dicho se ocupa todo mundo: cada cual puede decir lo suyo, como quiera y como pueda. Incluso puede prescindir de decirlo, puesto que el lenguaje, siendo social, no nos compromete. Todos se ocupan de lo dicho, lo cual incluye a los filósofos que analizan lo enunciado. Pero ¿quién se ocupa de lo pensado? Debemos creer que yo mismo, es decir, cada uno, cada cual que se asume como sujeto de su propio pensar, de eso que estaría antes del decir. No antes del lenguaje, pero sí antes de la duda: ¿hay alguien que no esté seguro de sus propios pensamientos?

\section{Conclusión}

En el tiempo, el decir se ordena cada vez más, ya que los filósofos y otros analistas del decir nos han contado el mundo. Entre la afirmación de que el cosmos se origina en el agua primordial y la afirmación de que antes de decirlo hay que ver si es posible pensarlo, hay un desplazamiento de pensar el mundo hasta pensar el pensamiento. Y cuáles son sus límites y sus leyes. El decir acerca de cómo son las cosas deja paso al decir acerca de cómo pensamos que son las cosas. Los argumentos de la narratividad —que nos cuentan cómo son las cosas - son lo que nos establecen mutuamente para convertirnos en un diálogo. Si bien esto no nos resuelve las dudas, nos otorga el consuelo de pertenecer a un mundo que sí puede ser pensado y que puede ser dicho, aunque no se comprenda. Somos un diálogo, sin importar que sea trunco, incomprensible, frondoso de confusos follajes. Si bien nos extrae de nosotros mismos, el decir, finalmente, nos entrelaza, nos regala un fondo común con la esperanza de que nuestros pensamientos sean agua del cauce que se mueve entre nosotros: el anhelo de que alguien pueda escuchar este decir.

\section{ADENDA}

El lenguaje entre los sordomudos de nacimiento surge de una necesidad de articular experiencias. La necesidad inventa el medio. Ante la ausencia del decir, lo pensado o lo comprendido requieren de ciertas claves para comunicarlo de forma análoga a los otros, sordomudos o no. En todo origen del lenguaje, tienen que haber sido al menos dos los que inventaron la primera palabra: solo hasta que hay un acuerdo de que el enunciado significa determinadas cosas es que surge el lenguaje. En tanto no se origina ese pacto, estamos ante articulaciones desarticuladas. El ejemplo es el extranjero al que nadie entiende en el otro país. El origen social y comunicacional de las palabras pareciera indicarnos que el idioma no está hecho para una sola persona. Necesitamos la colectividad de usuarios, el grupo de hablantes que denominará al mundo con su lenguaje. El relato del "Génesis" aclara esa función denominadora: el primer ser humano es creado con el objetivo de darle nombre a las cosas, para que creara el lenguaje, para que "sea un diálogo" con las cosas mientras se crean los demás humanos. Conforme a la versión canónica, a su tiempo llega Eva y lo segundo que hace Adán es enseñarle el idioma, pues primero tuvo que pensarlo.

Detrás del tema del lenguaje como posesión social se mueve el asunto del individuo y de la comunidad en la perspectiva del ser. El individuo y la especie tienen propósitos comunes de supervivencia, pero sus agendas son distintas. Si el individuo está bien, la comunidad está bien, pues no tiene que cuidar de él. Las vidas, individuales, podrían conocerse a sí mismas en la vivencia de su propia vida: se pueden conocer si cuidan de sí mismos. Es lo que se ha llamado la cura. Pensarse a sí mismo supone ver los límites de uno mismo, que son precisamente los de su supervivencia, que tendrá mejores probabilidades cuando se entrelaza a las de los 
demás. Por eso hay que decírselo a los demás. Hay que ejercer una cura, ese cuidado del ser, lo cual implica dos situaciones: la primera mantener el ser nuestro y la segunda pensar ese ser que somos en el lenguaje, "ser un diálogo" para poner el cuidado de nuestro ser en el cuidado del ser de la comunidad.

\section{REFERENCIAS}

Alatorre, A. (1993). Ensayos sobre crítica literaria. México: Conaculta.

Aristóteles. (2002). Retórica. (A. E. Ramírez, trad.). México: UNAM.

Crane, S. (2005). Los jinetes oscuros: poesía completa. México: Azafrán y Cinabrio.

Heidegger, M. (2001). Hölderlin und das Wesen der Dichtung, Gesamtausgabe, Band 4, Erläuterungen Hölderlins Dichtung. [Hölderlin y la esencia de la poesia. Aclaraciones a la poesía de Hölderlin]. Frankfurt am Main: Vittorio Klostermann.

Okakura, K. (2001). The book of tea. California: Shambhala.

Paz, O. (2004). Obra poética II (1969-1998). Obras completas, tomo 12. México: FCE.

Nicol, E. (1990). Ideas de vario linaje. México: UNAM.

Xirau, R. (1971). Palabra y silencio. México: Siglo XXI.

Huidobro, V. (2006). Altazor o el viaje en paracaídas. México: Azafrán y Cinabrio.

Schiappa, E. (1992). Rhêtorikê: What's in a Name? Toward a Revised History of Early Greek Rhetorical Theory. The Quarterly Journal of Speech, 78, 1-15.

\section{Notas}

1. La base derivativa en indoeuropeo sería äbel- que llevaría también al vocablo apple, en inglés. El origen común de conjuntos de vocablos provenientes de diversos idiomas no hace sino confirmar que la variación lingüística converge con una variación conceptual. A la inversa, una misma base conceptual puede llevar a variantes de lenguaje, como la raíz indoeuropea * rei-2, que conduce al latín rivus [río] y, más allá, se relaciona con la raíz er-3, que tiene el sentido de mover (porque el río se mueve); y, por otra parte, la raíz * sreu-, que conduce al griego $\rho \dot{\varepsilon} \omega \omega$ [correr] con el mismo sentido conceptual (porque quien corre se mueve). Por eso es y no es reiterativo decir que "el río corre".

2. El poema de Hölderlin citado por Heidegger (2001) dice: "seit ein Gespräch wir sind / Und hören können voneinander". Lo traduzco así, literalmente: "dado que un diálogo somos / Y escucharnos podemos mutuamente".

3. Lo traduzco así: a fin de comprender una obra maestra, debes mantenerte humilde ante ella y aguardar con la respiración ansiosa su más sutil expresión. Un eminente crítico Sung cierta vez hizo una sugerente confesión, dijo “en mi juventud elogié al maestro cuyas obras me gustaban, pero conforme maduró mi juicio me elogié a mí mismo porque me gustaba lo que los maestros eligieron para que me gustara".

4. En griego, $\rho \dot{\varepsilon} \omega$ (rhéo) [correr] nombra el fluir. Por su parte, el vocablo $\hat{\rho} \tilde{\eta} \mu \alpha$ (rhema) palabra, es el decir activo, el verbo

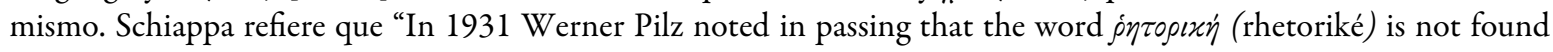
prior to Plato" (1992, p.1).

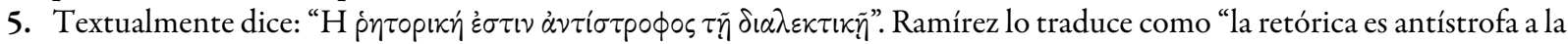

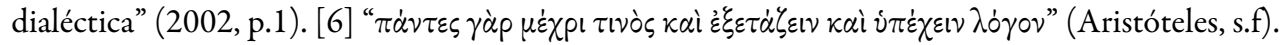

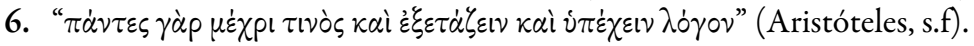

7. Nicol planteaba que la filosofía es un "oficio verbal", aunque "el ser habla del ser por boca de la filosofía" (1990, pp. 201-205). Ante el hecho de que la filosofía es “cosa de palabras”, Ramón Xirau replica: "lo que queda por ver es si es tan solo cosa de palabras" (1971, p. 1).

\section{BY-NC-ND}

